\title{
O PROJETO CLÍNICO-ASSISTENCIAL E DE FORMAÇ̃̃O DO INSTITUTO RAUL SOARES: POSIÇÃO DE LAÇO COM A REDE
}

THE CLINICAL-ASSISTANCE AND TRAINING PROJECT AT THE RAUL SOARES INSTITUTE: A BOND POSITION WITH THE NETWORK

\section{EL PROYECTO CLÍNICO-ASISTENCIAL Y DE FORMACIÓN DEL INSTITUTO RAÚL SOARES: POSICIÓN DE VÍNCULO CON LA RED}

\author{
Juliana Meireles Mota ${ }^{*}$ \\ Marconi Martins da Costa Guedes ${ }^{* *}$
}

\begin{abstract}
RESUMO
A proposta de um projeto clínico-assistencial e de formação para o Instituto Raul Soares está assentada em uma pergunta fundamental: qual a vocação clínica desta instituição, quais são os seus princípios operadores da clínica e das suas atividades assistenciais e como podemos transmitir essa vocação clínica aos nossos trabalhadores e parceiros de trabalho da rede de atenção psicossocial? É com base nessa pergunta que desenvolvemos este texto, expondo algumas ideias sobre como tem se dado a efetivação de um projeto clínico-assistencial e de formação de uma instituição de tratamento e ensino que privilegia uma posição de laço com a rede. $\mathrm{O}$ nosso orientador para o projeto institucional do IRS é a palavra, e a nossa causa, o laço com o território, com a rede, com a cidade, para a vida do sujeito falante.
\end{abstract}

Palavras-chave: Instituto Raul Soares. Projeto clínico-assistencial. Formação. Rede.

\section{ABSTRACT}

The proposal of a clinical-assistance and training project for the Raul Soares Institute (RSI) is based on a fundamental question: what is the clinical vocation of this institution, what are its principles, operating the clinic and its assistance activities and how we can transmit this clinic vocation to our employees and workmates within the psychosocial assistance network? It is based on this question that we have developed this work, unveiling some ideas about how the effectiveness of a clinical-assistance project and the formation of a treatment and teaching institution that privileges a position of bond with the network is being developed. Our guideline to the RSI's institutional design is the speech, and our cause is the bond with the territory, with the network, the city, for the life of the speaking subject.

\footnotetext{
* Mestra em Psicologia pela Universidade Federal de Minas Gerais (UFMG), psicanalista, membro aderente da Escola Brasileira de Psicanálise (EBP-MG), diretora técnico-assistencial do Instituto Raul Soares (IRS/Fhemig) e coordenadora do Programa de Residência Multiprofissional em Saúde Mental do IRS/Fhemig. Endereço: Instituto Raul Soares, Avenida do Contorno, 3017 Santa Efigênia, Belo Horizonte-MG, Brasil. CEP: 30110-013. E-mail: julianameirellesmotta@gmail.com.

** Mestre em Estudos Psicanalíticos pela UFMG, coordenador do Núcleo de Ensino e Pesquisa do IRS/Fhemig, coordenador adjunto e docente do Programa de Residência Multiprofissional em Saúde Mental do IRS/Fhemig, psicólogo do IRS/Fhemig. Endereço: Instituto Raul Soares, Avenida do Contorno, 3017 - Santa Efigênia, Belo Horizonte-MG, Brasil. CEP: 30110-013. E-mail:marconi_martins@hotmail.com.
} 
Keywords: Raul Soares Institute. Clinical-assistance project. Formation. Network.

\section{RESUMEN}

La propuesta de un proyecto clínico-asistencial y de formación para el Instituto Raul Soares está asentada en una pregunta fundamental: ¡cuál es la vocación clínica de esta institución, cuáles son sus principios operadores de la clínica y de sus actividades asistenciales y cómo podemos transmitir esta vocación clínica a nuestros trabajadores y socios de trabajo de la red de atención psicosocial? A partir de esta pregunta desarrollamos este texto, exponiendo algunas ideas sobre cómo se ha dado la efectivación de un proyecto clínico-asistencial y de formación de una institución de tratamiento y enseñanza que privilegia una posición de vínculo con la red. Nuestro orientador para el proyecto institucional del IRS es la palabra y nuestra causa el vínculo el territorio, con la red, con la ciudad, para la vida del sujeto hablante.

Palabras clave: Instituto Raúl Soares. Proyecto clínico-asistencial. Formación. Red. assistência psiquiátrica não foge à regra. Permanecem atuais as formulações da representação social da loucura nas tentativas de ilustrá-la definindo o louco como o outro da vontade, o outro da alienação, como alguém que perdeu parte da humanidade e alienou-se de uma parte de si mesmo. São vários os discursos estratégicos que tentam dar conta desta condição "desumana" e de "ignorância" que envolve os sujeitos nomeados como doentes mentais. O filósofo francês Michel Foucault trabalhou em diversas obras a história da loucura, nas quais estudou como se deu a passagem da loucura de manifestação de forma do saber para doença mental. Segundo Foucault (1996),

Desde a Alta Idade Média, o louco é aquele cujo discurso não pode circular como o dos outros: pode ocorrer que sua palavra seja considerada nula e não seja acolhida não tendo verdade nem importância, não podendo testemunhar na justiça, não podendo autenticar um ato ou um contrato [...] Era através de suas palavras que se reconhecia a loucura do louco; elas eram o lugar onde se exercia a separação; mas não eram nunca recolhidas nem escutadas (pp. 10-11).

O discurso organicista e biológico tem o asilo como seu lócus de produção e trabalha unicamente com a tradição do pensamento médico, tendo o corpo 
do paciente como um objeto no qual o uso abusivo de medicação e a prática puramente psiquiátrica se legitimam em torno deste discurso, mantendo, assim, a ordem da segregação asilar. O discurso preventivista, por sua vez, reduz o indivíduo à massa, em que o singular está completamente fora e dentro do qual se firmam programas que endereçam ao Estado ações intervencionistas, colocando o paciente em uma condição de periculosidade e ameaça ao outro. Hoje a judicialização da saúde demonstra claramente essa situação. Por último, encontra-se o discurso psicoterápico colocando-se no atendimento no tecido público sem qualquer articulação com os vários atravessamentos que operam no trabalho comunitário, sem se implicar com a realidade social e se bastando em uma posição de suspensão e alienação.

A constituição da medicina mental no Brasil aconteceu no meio do século XIX e seguiria uma trajetória higienista até as primeiras décadas do século XX. A sistematização da prática fez parte de um projeto médico-social, constituindo-se numa exercício de controle e disciplina social. Seguindo à risca os pressupostos higiênicos, propondo um projeto de higiene moral, essa proposta se encaixou no moderno projeto iluminista de transformação da natureza para possibilitar a produção nacional da felicidade humana na ordem social.

Dessa maneira, o homem idealizado desse tempo seria regulado pelas normas sociais. Nasceu uma possibilidade de o louco se integrar, mas com base numa lógica paradoxal da cidadania: ele deveria transformar-se em um sujeito da razão e da vontade, e sua desrazão seria corrigida por um processo ortopédico de reabilitação moral.

Com efeito, o louco não se insere ele mesmo, mas sim como um arremedo de cidadão. Sua subjetividade não existe pelos pressupostos da cidadania e da ordem social. Sua exclusão permanece, e é o Estado agora que arbitra sobre ele. Sua liberdade e seus bens estão assujeitados a um código de administração social.

Birman (1991) relata várias práticas que constituirão a tentativa de articular o louco à sociedade, coroando, dessa forma, o que ele nomeia de uma "pedagogia da sociabilidade" e constituindo-se como uma forma-limite do aprendizado da cidadania. Práticas como a praxiterapia dos anos 20, a psicofarmacologia dos anos 40 e 50, as comunidades terapêuticas e a psicoterapia institucional nos anos 40 e 50, presentes nos Estados Unidos e Europa, os projetos de psiquiatria comunitária (modelo norte-americano), a psiquiatria de setor (modelo francês), a psiquiatria democrática italiana com o discurso político de Baságlia e a experiência de Gorízia demonstrariam o esforço de transformar o louco em cidadão. Falharam como modelos únicos e fechados, pois o louco não se inscreve no coletivo do modelo de razão apregoado. 
A Reforma Psiquiátrica se construiu nos pressupostos fundamentais dos "direitos" do doente mental e sua cidadania, desprovida da condição de que ele primeiramente devia se adaptar à prática coletiva. Ele tem direitos e é, por si só, independente de sua condição clínica. Ela abordaria o louco como cidadão, com toda polêmica que essa premissa levanta, pois ele, até o momento, era considerado um indivíduo "fora de sua razão", "incapaz de responder pelos seus atos" e juridicamente "insano e irresponsável”. Segundo Delgado (1992), a Reforma deixou de ter um caráter técnico-administrativo, ou seja, não se tratava apenas de propor melhores condições de tratamento e um acesso mais rápido e competente aos serviços de saúde mental. Tratava-se, sim, de desinstitucionalizar, desconstruir o manicômio e construir um novo cotidiano que oferecesse uma nova forma de lidar com a loucura e o sofrimento psíquico.

Não se estava mais trabalhando com o homem da razão do projeto iluminista. Todas as práticas alternativas à instituição psiquiátrica clássica que tentaram medir a distância entre a loucura e a razão não se sustentaram. Se essa mediação não se faz possível, é também impossível o preenchimento terapêutico do espaço da loucura e o homem da razão.

Os loucos não se localizam socialmente, nem clinicamente na igualdade. Por sua linguagem delirante e desorganizada, existe uma demarcação territorial de um espaço a ser reconhecido e trabalhado.

A partir do III Congresso Mineiro de Psiquiatria, emergiram reivindicações em relação ao tipo de atendimento prestado aos pacientes psiquiátricos. Nesse contexto, a comunidade de trabalhadores do Instituto Raul Soares (IRS) reivindicaram a realização de uma reestruturação em seu modelo assistencial. Em 1980, ocorreria o I Seminário Interno do IRS, no qual se produziu um novo regimento interno, com novas diretrizes em que se redefiniu um novo modelo assistencial, no qual recuperação e ressocialização do usuário passaram a ser orientadores, em que novas equipes terapêuticas se organizaram com a perspectiva de um trabalho interdisciplinar.

Com o advento da Reforma Psiquiátrica e consequentemente com a consolidação da política de Saúde Mental do Ministério da Saúde, o IRS estabeleceu uma proposta assistencial, ao longo desse período pós-anos 90, oscilante. Ora com avanços políticos e clínicos de acordo com a reforma sanitária vigente e articulada com os princípios do Sistema Único de Saúde (SUS), ora recuando para um discurso da predominância das especialidades clínicas e centralizando o tratamento no hospital psiquiátrico sem se articular com as redes de atenção psicossociais dos municípios. 
As consequências dessa posição são graves em termos de um trabalho institucional, pois isola e silencia tanto o caso clínico quanto os trabalhadores, operando, assim, um efeito imaginário em que os espaços de linguagem são substituídos pela amostragem e quantificação de atendimentos.

Não se pode falar de um trabalho clínico e ético em um contexto onde a pobreza do discurso manicomial encontra-se assentada. Uma prática clínica deve operar no sentido contrário ao da exclusão, uma prática que possa produzir um coletivo de grande expressividade, constituído pela articulação de diversas singularidades entre si, em que o sujeito possa sustentar a sua diferença sem precisar ser excluído do social, possibilitando a diferença como tal: fazê-la caber. Uma prática na qual se deve manter uma interlocução interdisciplinar entre grupos de trabalho de dentro e de fora do hospital, em que se deve manter atenção às novidades que as diversas categorias profissionais trazem ao debate e que devem integrar-se a uma elaboração técnica rigorosa e articulada com o pensamento contemporâneo.

Dessa maneira, a atual proposta de um projeto clínico para o IRS está assentada em uma pergunta fundamental: qual é a vocação clínica dessa instituição e como podemos transmiti-la aos nossos parceiros de trabalho da rede de atenção psicossocial? Essa é uma questão que toca diretamente a uma posição ética, uma ética clínica, e se falamos de clínica no trabalho público, esse mesmo significante está enlaçado ao significante cidadania. Ali, onde o singular do sujeito aparece e é acolhido, a cidadania se faz. Assim, temos como objeto primordial do nosso projeto restituir à instituição a sua função clínica e social articulados, sem separação.

É preciso colocar no centro do trabalho institucional o ato da palavra, mais precisamente, o ato que cria a palavra. Segundo Viganò (1999), a proposta é repensar o lugar da palavra a partir de um diagnóstico de um discurso transclínico que diz respeito à posição subjetiva diante da castração e centrada sobre a letra do gozo.

Assim, perguntamo-nos: para que serve a instituição? De que instituição nós estamos falando? Para Zenoni (2000), em seu texto exemplar "Qual a instituição para o sujeito psicótico?”, a instituição existe para atender a uma necessidade social e clínica. Há uma articulação entre a função social que ela tem com uma função terapêutica, e, entre essas duas funções, uma terceira via que se constitui como a necessidade social de uma resposta institucional à clínica, esta que exige uma estrutura coletiva de resposta.

Falamos assim de uma posição adotada pelo IRS, que, pelos vários espaços de linguagem, como sessões clínicas, reuniōes de equipe, encontro dos colegiados, 
reuniōes gerais, assembleias de pacientes e técnicos, seminários teórico-clínicos e apresentação de pacientes, dispara modificações nas condições da massa institucional, operando mudanças dos discursos, operando a passagem da lógica da segregação à saída do um a um, restaurando o Outro da palavra e mudando o instituído.

Citando Zenoni (2000, p. 19): “[...] é a psicose que nos ensina sobre a estrutura e que nos ensina sobre as soluções que ela mesma encontra para fazer face a uma falta central do próprio simbólico. É na escola da psicose que nos colocamos para aprender como praticar".

Assim nos colocamos em uma posição de aprendizagem em relação à clínica, posição que dispara efeitos na instituição, desde a porta de entrada, nas equipes de internação até ao trabalho administrativo, posição que faz girar os discursos e que modula a ferocidade do "discurso do mestre" institucional. De uma posição tradicional da instituição que tudo sabe sobre o sofrimento psíquico, constituindo-se, dessa maneira, em um Outro erotômano, a uma posição de sujeito suposto não saber.

Essa é a nossa proposta de trabalho: a palavra no centro da instituição, a clínica como a única razão para estarmos aqui. Que sejam vários os discursos, mas que estejam em torno do vazio que o caso clínico inaugura, como escreve Kaufmanner (2015) no seu precioso texto sobre a prática de apresentação de pacientes, como uma pausa na falação institucional: momento em que a instituição se cala para escutar um, momento de suspensão, de escuta ao sujeito. Momento precioso, delicado, em que técnicos e funcionários silenciam a partir de uma transferência ao trabalho clínico. Nessa subversão institucional, nessa operação que causa uma descontinuidade no discurso burocrático das regras, normas e protocolos do serviço, algo novo surge a partir da palavra do paciente, causando um giro nos discursos que constituem a operação lógica do trabalho cotidiano.

Assim, caracterizado como hospital de ensino, o IRS se coloca disposto a aprender com o caso clínico; disposto, baseado no ensinamento de Lacan, a tocar o sujeito em cada paciente. A orientação é de que a instituição é que deve caber no caso clínico, não o contrário.

Mas não podemos falar da clínica sem falar no laço social. Nosso ofício é resgatar esse laço do sujeito em relação ao Outro e, dentro dessa lógica, a instituição também deve trabalhar nessa direção, na de um trabalho em rede. Este, em primeiro lugar, deve estar assentado em uma organização do serviço na perspectiva da rede, ou seja, mantendo-se estruturado para que seus trabalhadores e os demais trabalhadores que participam dessa rede psicossocial possam ir de um lugar a outro, de uma instituição a outra, de um operador a outro. 
A organização social vai se caracterizar por recursos predispostos, ou seja, existe uma política, um legislador ou um gestor que já determina previamente, de uma maneira quase automática, por onde as pessoas devem passar e que tais pessoas sejam selecionadas com base em seus atos, seus comportamentos. Assim, essa rede social vai funcionar como um conjunto de trilhos, recebendo as pessoas pelos seus sintomas em pontos de recepção já preestabelecidos. Essa é uma rede que trabalha de uma maneira segregatícia, rica em pontos de concentração, paradoxal, múltiplos lugares que recebem um portador de um sintoma específico, por exemplo, o toxicômano, a anoréxica, o alcoolista, etc. Esse tipo de organização de processo de recepção vai produzir no sujeito que procura ajuda um efeito de identificação social.

Viganò (1999) defende outra lógica de o sujeito circular na rede, pois esta, propriamente como tal, não é boa nem má, não tem intenções, mas identifica e segrega. A mudança de direção opera quando se considera que quem dá a direção do percurso é o próprio sujeito. O que está em jogo é uma transferência, que vai permitir que um sintoma vai ser tratado na rede como uma escolha, como um ato do sujeito e trabalhado a partir da construção do caso clínico.

É na perspectiva do trabalho em rede e pela aposta do caso deslizando por ela que compreendemos o IRS como um lugar de passagem, pontual, ligeiro, acolhedor, mas sem causar aderência, sem se concentrar em si mesmo e sem se autorreferenciar, mantendo-se em um movimento constante de esvaziamento, fazendo da sua porta de entrada uma porta-giratória. $\mathrm{O}$ nosso orientador para o projeto institucional do IRS é a palavra, e a nossa causa, o laço com o território, com a rede, com a cidade, para a vida do sujeito falante.

O Instituto Raul Soares também tem cumprido outra função de fundamental importância como hospital-escola: a promoção da formação em saúde mental dos seus trabalhadores, residentes, estagiários, futuros trabalhadores do SUS.

A necessidade crescente de ampliação dos espaços de formação para trabalhadores do SUS é uma realidade no Estado de Minas Gerais e em todo Brasil. A implantação do SUS traz consigo a necessidade de mudanças nos processos de formação, de trabalho e de gestão de saúde. Na ausência de mudanças na formação, torna-se mais difícil transformar também as práticas de trabalho e de gestão.

Entre os mais importantes problemas enfrentados pelo SUS relacionados aos recursos humanos encontra-se a formação dos profissionais de saúde. Estes raramente são qualificados adequadamente para o trabalho em equipe, interdisciplinar, realizado em redes de atenção descentralizadas e regionalizadas, que assegurem a integralidade e a universalidade dos cuidados. 
Tal problema é particularmente relevante na saúde mental, na qual os avanços obtidos na implantação dessas redes contrastam agudamente com uma formação que reduz a aspectos estritamente técnicos a vasta gama de questôes envolvidas no campo dos transtornos psíquicos e relega a segundo plano o estudo das políticas públicas necessárias para abordá-los devidamente, na perspectiva da atenção psicossocial, do trabalho em rede e da promoção de cidadania.

Os profissionais que hoje atuam nos novos serviços de saúde mental vêm compensando, com seu empenho e criatividade, essas lacunas na formação. Contudo, conforme os serviços se ampliam, oferecendo cobertura a uma parcela sempre crescente da população, tornam-se cada vez mais necessárias a clareza conceitual e a reflexão crítica sobre o trabalho, sob pena do empobrecimento e da automatização da prática que desenvolvem.

Visando ao enfrentamento dessa realidade, o Instituto Raul Soares tem criado, a cada dia, vários espaços de formação, ensino e pesquisa para os seus trabalhadores e futuros trabalhadores da saúde mental (residentes e estagiários). Credenciado pelo Ministério da Educação como um hospital-escola, tem cumprido assim, além da sua vocação clínica, a sua vocação na formação em saúde mental no âmbito do SUS.

Tal vocação tem se dado por meio de várias frentes. A partir da realização de convênios com diversas instituições de ensino, o IRS oferece campo de estágio e internato para diversos alunos das instituições conveniadas, colocando-os em contato com o campo da saúde mental e promovendo a sua formação.

O IRS também tem garantido para os seus trabalhadores e demais trabalhadores da rede uma formação em serviço por meio dos vários espaços instituídos, tais como sessões clínicas, reuniōes de equipe e de colegiados, seminários teóricoclínicos, supervisões clínicas e apresentação de pacientes, promovendo a circulação dos diversos saberes e discursos na instituição. Em todas essas modalidades de transmissão, os trabalhadores da saúde mental têm se colocado na posição de aprender com o caso clínico, operando, a partir do caso, uma mudança sobre a própria prática.

Há também um volume significativo de pesquisas realizadas na instituição, que se originam da problematização do fazer cotidiano dos seus trabalhadores e do interesse das universidades e faculdades parceiras que endereçam ao IRS vários projetos de pesquisa, alguns em nível de mestrado e doutorado, possibilitando a construção de práticas e investigações teórico-clinicas no campo da saúde mental. Em muitas dessas pesquisas, os próprios trabalhadores da instituição conduzem ou são convidados a participarem, produzindo, assim, efeitos de instituir no cotidiano institucional os fundamentos de métodos de pesquisa como mais uma forma de pensar sobre a prática, fazendo avançar a sua práxis. 
A Residência de Psiquiatria do Instituto Raul Soares, com meio século de existência formando psiquiatras, e o seu Programa de Residência Multiprofissional em Saúde Mental são outros importantes espaços de formação existentes. Dentro das residências, há a orientação e o esforço crescente de que os residentes circulem cada vez mais pela rede municipal durante o seu período de curso, promovendo a sua formação não somente dentro dos muros da instituição. Assim como no projeto institucional do IRS, o laço com a formação tem se dado para fora, para a rede, para a cidade, pelas parcerias com os diversos dispositivos e serviços substitutivos de saúde mental do Município de Belo Horizonte, promovendo a formação dos residentes no território. Entende-se que a formação dos residentes nos serviços substitutivos, na rede, redimensiona o lugar dos saberes psi, convocando os residentes a pensamentos, estudos e questôes inabituais no currículo acadêmico, proporcionando aos futuros trabalhadores de saúde mental o contato com um modelo assistencial no qual devem atuar futuramente e formatando a sua identidade como futuro trabalhador do SUS. Segundo o psicólogo baiano Oliveira (2002), um processo de formação opera num regime de produção de identidade:

Do ponto de vista prático, eu queria pensar com vocês que um processo de formação é um processo que fundamentalmente opera num regime de produção de identidade. Nós podemos pensar a formação como um processo no qual você vai buscar selecionar algumas experiências e aqueles que passaram por estas experiências selecionadas, ao final, terão uma identidade que decorre exatamente de terem sido partícipes deste conjunto de experiências planejadas, experiências previamente escolhidas e eleitas como experiências indicadas para que estes sujeitos ao final desta sequência possam produzir uma certa identidade (p. 135).

Assim, entendendo que o processo de formação opera na formação de identidades, não é absolutamente indiferente o tipo de experiência de ensino/ formação que uma instituição seleciona para oferecer a seus trabalhadores. No IRS, instituição na qual há toda uma tradição na relação entre ensino, formação e clínica, privilegia-se a formação em serviço, orientada pelo caso clínico e na perspectiva de uma posição de laço com a rede. Desse modo, a aposta é de que as identidades dos nossos profissionais possam ser produzidas com base numa posição de aprendizagem em relação à clínica. Esse é um princípio orientador das experiências de formação oferecidas pelo IRS e o desafio que temos nos colocado em nosso cotidiano. 


\section{REFERÊNCIAS}

Birman, J. (1991). A cidadania tresloucada. In J. Bezerra \& P. Amarante. (Orgs.), Psiquiatria sem hospicio: contribuiçôes ao estudo da reforma psiquiátrica. (pp. 71-90). Rio de Janeiro: Relume Dumarà.

Delgado, P. G. G. (1992). Reforma psiquiátrica e cidadania. Revista Saúde, 35, 80-84. Foucault, M. (1996). A ordem do discurso. São Paulo: Loyola.

Kaufmanner, H. (2015). Um relato imperdoável. Revista de Psicanálise, 14, 113-117.

Oliveira, M. V. (2002). Hospital psiquiátrico versus serviços substitutivos: um embate no campo do ensino. In M. Abou-yd (Org.), Hospitais psiquiátricos: saidas para o fim. (pp. 129-147). Belo Horizonte: Fhemig.

Viganò, C. (1999, setembro). A construção do caso clínico em saúde mental. Revista Curinga, 13, 39-48.

Zenoni, A. (2000, junho). Qual a instituição para o sujeito psicótico. Abrecampos: Revista de Saúde Mental do Instituto Raul Soares - Fhemig, 1, 12-31. 